\title{
Age-Related Changes in Bone Remodelling and Structure in Men: Histomorphometric Studies
}

\author{
Juliet Compston \\ Department of Medicine, Cambridge University Hospitals NHS Foundation Trust, Cambridge CB2 OQQ, UK \\ Correspondence should be addressed to Juliet Compston, jec1001@cam.ac.uk \\ Received 13 April 2011; Accepted 22 August 2011 \\ Academic Editor: Pawel Szulc \\ Copyright () 2011 Juliet Compston. This is an open access article distributed under the Creative Commons Attribution License, \\ which permits unrestricted use, distribution, and reproduction in any medium, provided the original work is properly cited.
}

Histomorphometric studies of the age-related changes in bone remodelling and structure in men are relatively sparse and mainly limited to the iliac crest. The available data indicate that loss of trabecular bone is predominantly due to decreased formation at the level of individual bone remodelling units and that an increase in remodelling rate does not play a major role. The main structural consequence of the changes in bone remodelling is trabecular thinning. In cortical bone, an age-related reduction in cortical width and increase in porosity have been demonstrated at several skeletal sites. However, the alterations in bone remodelling responsible for these changes remain to be established.

\section{Introduction}

Loss of bone with ageing is a universal phenomenon affecting both men and women and is associated with reduced bone strength and increased fracture risk. Whereas the changes in bone remodelling and structure underlying bone loss have been relatively well studied in women, there have been few studies in men. This paper reviews the bone histomorphometric data available in men and discusses the similarities and differences in cellular and structural mechanisms of bone loss in men and women.

\section{Cellular and Structural Mechanisms of Bone Loss}

In trabecular bone, bone loss may occur as a result of increased remodelling rate and/or a negative remodelling balance at the level of individual bone remodelling unit of basic multicellular unit (BMU) (Figure 1). The remodelling balance is determined by the amount of bone resorbed and that subsequently formed; hence a negative balance may be the result of increased resorption, reduced bone formation, or a combination of the two. The structural changes occurring during bone loss are determined by the underlying alterations in bone remodelling. An increase in remodelling rate, particularly if resorption within individual BMUs is also increased, will favour trabecular penetration and loss of connectivity whereas remodelling imbalance due to decreased formation in the BMU will predominantly be associated with trabecular thinning and preservation of trabecular microarchitecture. However, as trabecular thinning progresses a point will be reached when a resorption cavity of normal depth can result in trabecular penetration.

Cortical bone loss results from changes in both endocortical and intracortical remodelling. In addition, cortical thickness is influenced by the rate of periosteal apposition. As in cancellous bone, these structural alterations are determined by changes in remodelling rate and balance.

\section{Strengths and Limitations of Bone Histomorphometry}

In humans, histomorphometric studies of age-related changes in bone are mostly restricted to iliac crest bone. Bone loss during ageing varies according to skeletal site, and thus the iliac crest may not always be representative of the rest of the skeleton. Furthermore, there is a large measurement variance associated with bone histomorphometry. However, bone histomorphometry remains the only technique currently 


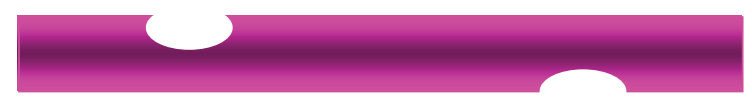

Normal

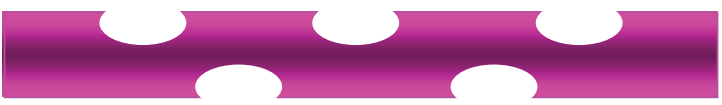

Increased remodelling rate

(a)

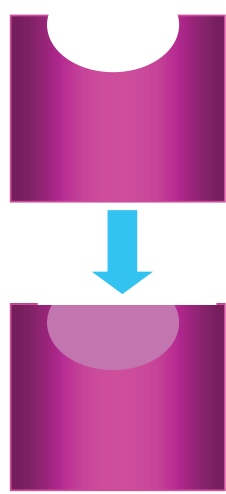

Balance

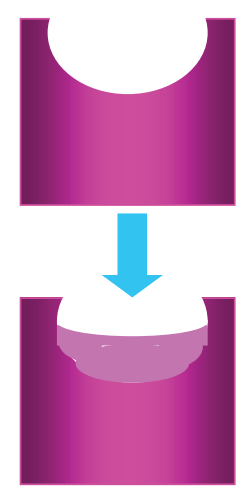

Imbalance

(b)

FIGURE 1: Mechanisms of trabecular bone loss. (a) Increased remodelling rate, (b) negative remodelling imbalance.

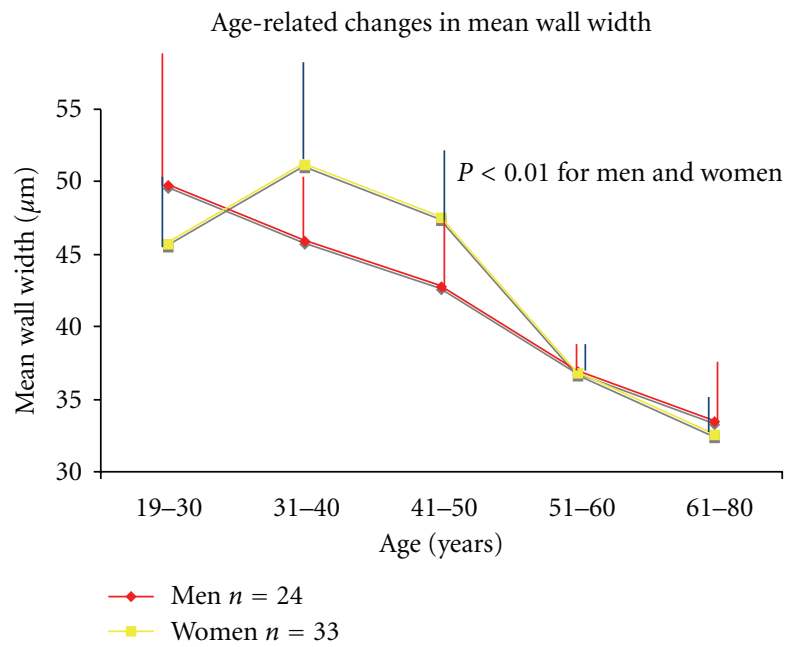

FIGURE 2: Age-related changes in mean wall width in healthy men and women (see [1]).

available that enables detailed assessment of remodelling rate, remodelling balance, and cellular activity.

\section{Age-Related Changes in Trabecular Bone Remodelling and Structure in Men}

Histomorphometric studies of age-related changes in men have all been cross-sectional and have contained relatively small numbers of individuals. In iliac crest bone a decrease in trabecular bone volume with age in men has been reported, generally becoming detectable around the fifth to sixth decade of life [2-5]. In some studies, the rate of bone loss was similar to that observed in women, but in two larger studies trabecular bone loss was significantly greater in women than in men $[2,3]$.

In the vast majority of studies in men tetracycline labelling was not given, and hence changes in remodelling rate could not be directly assessed. However, in one study of 24 men across a wide age range in which tetracycline was given prior to biopsy, no clear age-related increase in remodelling rate was seen, in contrast to that observed in women [1]. Consistent with this observation osteoid surface, which reflects tissue level bone formation, does not show the same age-related increase in men as seen in women [4]. In contrast, there is consistent evidence that mean wall width, which reflects the amount of bone formed within individual BMUs, decreases with age both in men and women (Figure 2) $[1,6]$. Changes with ageing in the depth of resorption cavities are more difficult accurately to assess, and in men, no change was reported in one study whilst in another, a decrease in men, but not in women was reported although in women, a transient increase was noted around the time of the menopause $[7,8]$.

The available evidence thus indicates that, at least in iliac crest bone, trabecular bone loss in men is predominantly due to a negative balance within BMUs, which results mainly from a decrease in the amount of bone formed and that increased remodelling rate does not make a substantial 
contribution to bone loss. These conclusions are supported by the demonstration that trabecular thinning is greater and loss of trabeculae less prominent with ageing in men than in women $[5,9]$. Thus in a study of 49 men, a significant agerelated decrease in mean trabecular width was demonstrated with nonsignificant trends towards decreased trabecular number and increased trabecular separation. In women, however, there was a nonsignificant decrease in trabecular width and a significant decrease in trabecular number and increase in trabecular separation [9]. The results of more recent studies using high-resolution peripheral quantitative computed tomography (HRpQCT) suggest that these sexspecific patterns of bone loss are also seen in other parts of the skeleton [10].

\section{Changes in Cortical Bone Remodelling and Structure in Men}

Histomorphometric data on age-related changes in cortical bone in men are sparse. In addition, skeletal heterogeneity of changes is likely to be particularly evident as a result of differences in the weight-bearing properties at different sites, resulting in site-specific differences in the onset and rate of age-related bone loss [11]. Even within a single site, significant variations in cortical bone structure may be observed, as recently reported in the femoral neck [12].

Notwithstanding this variability, a decrease in cortical width during ageing in men has been reported at a number of skeletal sites [13-15]. Whether there are differences between men and women in the magnitude of age-related cortical thinning is uncertain; however, greater periosteal apposition and less endocortical resorption in men may result in lower rates of thinning. Most studies have shown an age-related increase in cortical porosity in both men and women in the iliac crest and other skeletal sites including the vertebrae, metacarpal, rib, and femur $[3,14,16]$. This is due at least in part to an increase in the size of individual pores, as assessed by Haversian canal diameter, although an increase in the number of pores may also contribute.

Age-related changes in cortical bone remodelling have not been well documented. In a cross-sectional study of 41 women and 23 men Brockstedt et al. [14] reported a decrease in mean wall width in iliac crest bone in women, but not in men. Since osteonal diameter and Haversian canal diameter increased with age in both sexes, the authors concluded that in men, an increase in resorption depth accounted for the negative remodelling imbalance. Similar findings were reported by Broulik et al. [17], but as direct measurements of resorption depth were not made in either study, this conclusion remains speculative. In the rib, mean wall width does not change with age in either sex [18]. Age-related changes in remodelling rate in cortical bone in men have not been reported; however, Brockstedt et al. [14] reported a significantly higher activation frequency in postmenopausal than premenopausal women, supporting an increase in remodelling rate during and after the menopause.

Overall, the available data support qualitatively similar age-related changes in cortical bone in men and women, with a decrease in cortical width and increase in cortical porosity.
However, there may be differences between the sexes in the magnitude of these changes; furthermore, the underlying alterations in bone remodelling remain to be clearly defined.

\section{Acknowledgment}

J. Compston is supported by NHS National Institute of Health Research and the Cambridge Biomedical Research Centre.

\section{References}

[1] S. Vedi, J. E. Compston, A. Webb, and J. R. Tighe, "Histomorphometric analysis of dynamic parameters of trabecular bone formation in the iliac crest of normal British subjects," Metabolic Bone Disease and Related Research, vol. 5, no. 2, pp. 69-74, 1983-1984.

[2] P. Courpron, P. Meunier, C. Bressot, and J. M. Giroux, "Amount of bone in iliac crest biopsy. Significance of the trabecular bone volume. Its values in normal and pathological conditions," in the 2nd International Workshop on Bone Histomorphometry, P. J. Meunier, Ed., pp. 39-53, Lyon, France, 1976.

[3] F. Melsen, B. Melsen, L. Mosekilde, and S. Bergmann, "Histomorphometric analysis of normal bone from the iliac crest," Acta Pathologica et Microbiologica Scandinavica. Section A, vol. 86, no. 1, pp. 70-81, 1978.

[4] S. Vedi, J. E. Compston, A. Webb, and J. R. Tighe, "Histomorphometric analysis of bone biopsies from the iliac crest of normal British subjects," Metabolic Bone Disease and Related Research, vol. 4, no. 4, pp. 231-236, 1982.

[5] J. E. Aaron, N. B. Makins, and K. Sagreiya, "The microanatomy of trabecular bone loss in normal aging men and women," Clinical Orthopaedics and Related Research, vol. 215, pp. 260271, 1987.

[6] P. Lips, P. Courpron, and P. J. Meunier, "Mean wall thickness of trabecular bone packets in the human iliac crest: changes with age," Calcified Tissue International, vol. 26, no. 1, pp. 13-17, 1978.

[7] E. F. Eriksen, L. Mosekilde, and F. Melsen, "Trabecular bone resorption depth decreased with age: differences between normal males and females," Bone, vol. 6, no. 3, pp. 141-146, 1985.

[8] P. I. Croucher, N. J. Garrahan, R. W. E. Mellish, and J. E. Compston, "Age-related changes in resorption cavity characteristics in human trabecular bone," Osteoporosis International, vol. 1, no. 4, pp. 257-261, 1991.

[9] R. W. E. Mellish, N. J. Garrahan, and J. E. Compston, "Agerelated changes in trabecular width and spacing in human iliac crest biopsies," Bone and Mineral, vol. 6, no. 3, pp. 331-338, 1989.

[10] S. Khosla, B. L. Riggs, E. J. Atkinson et al., "Effects of sex and age on bone microstructure at the ultradistal radius: a population-based noninvasive in vivo assessment," Journal of Bone and Mineral Research, vol. 21, no. 1, pp. 124-131, 2006.

[11] H. M. MacDonald, K. K. Nishiyama, J. Kang, D. A. Hanley, and S. K. Boyd, "Age-related patterns of trabecular and cortical bone loss differ between sexes and skeletal sites: a populationbased HR-pQCT study," Journal of Bone and Mineral Research, vol. 26, no. 1, pp. 50-62, 2011.

[12] P. M. Mayhew, C. D. Thomas, J. G. Clement et al., "Relation between age, femoral neck cortical stability, and hip fracture risk," Lancet, vol. 366, no. 9480, pp. 129-135, 2005. 
[13] P. Adams, G. T. Davies, and P. Sweetnam, "Osteoporosis and the effects of ageing on bone mass in elderly men and women," The Quarterly Journal of Medicine, vol. 39, no. 156, pp. 601615, 1970.

[14] H. Brockstedt, M. Kassem, E. F. Eriksen, L. Mosekilde, and F. Melsen, "Age- and sex-related changes in iliac cortical bone mass and remodeling," Bone, vol. 14, no. 4, pp. 681-691, 1993.

[15] S. Vedi, S. Kaptoge, and J. E. Compston, "Age-related changes in iliac crest cortical width and porosity: a histomorphometric study," Journal of Anatomy, vol. 218, no. 5, pp. 510-516, 2011.

[16] C. D. L. Thomas, S. A. Feik, and J. G. Clement, "Increase in pore area, and not pore density, is the main determinant in the development of porosity in human cortical bone," Journal of Anatomy, vol. 209, no. 2, pp. 219-230, 2006.

[17] P. Broulik, J. Kragstrup, L. Mosekilde, and F. Melsen, “Osteon cross-sectional size in the iliac crest. Variation in normals and patients with osteoporosis, hyperparathyroidism, acromegaly, hypothyroidism and treated epilepsia," Acta Pathologica et Microbiologica Scandinavica. Section A, vol. 90, no. 5, pp. 339344, 1982.

[18] H. M. Frost, "Tetracycline-based histological analysis of bone remodeling," Calcified Tissue Research, vol. 3, no. 1, pp. 211237, 1969. 


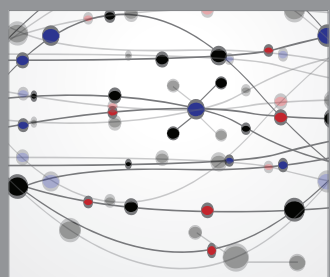

The Scientific World Journal
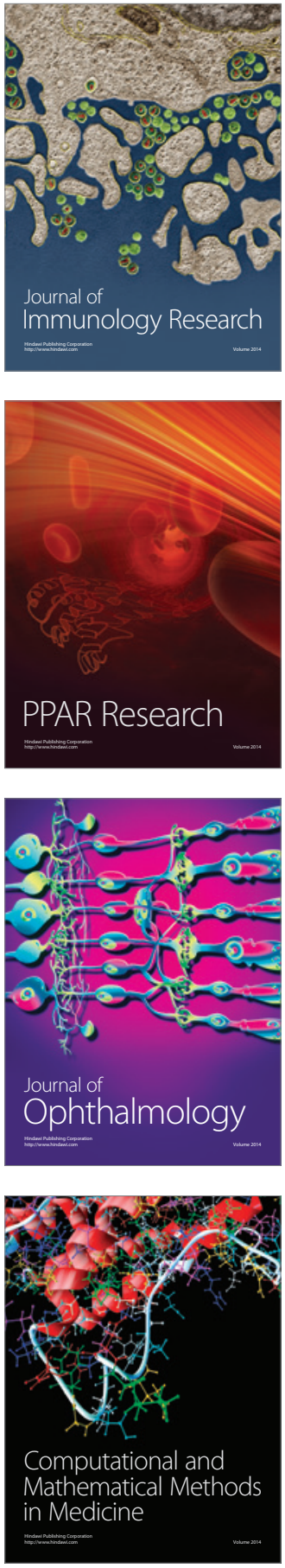

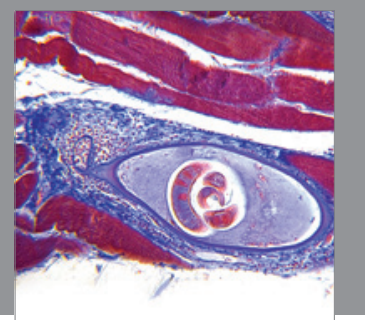

Gastroenterology

Research and Practice
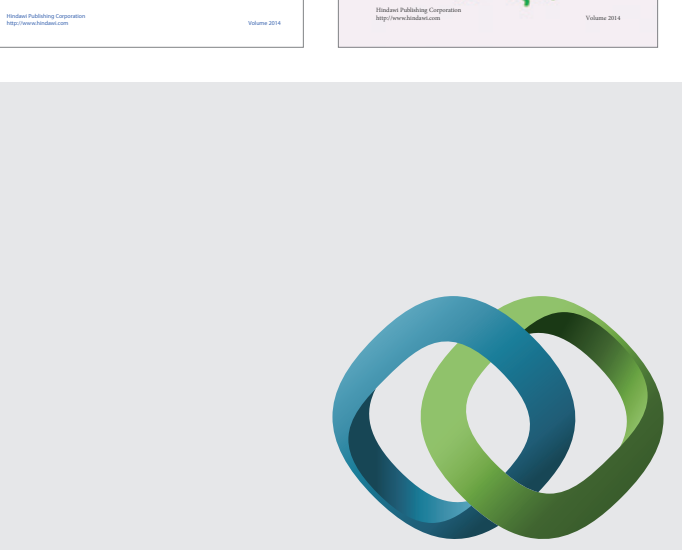

\section{Hindawi}

Submit your manuscripts at

http://www.hindawi.com
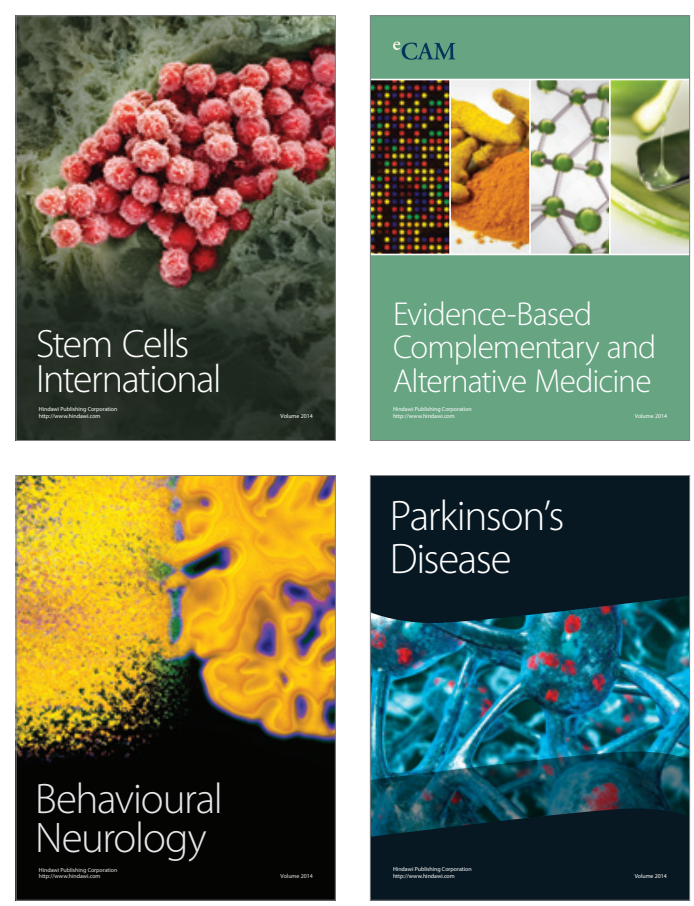

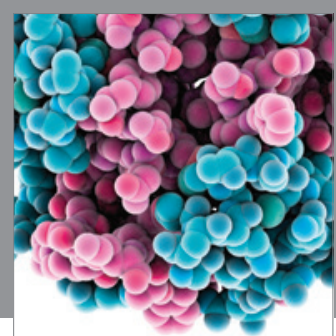

Journal of
Diabetes Research

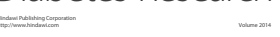

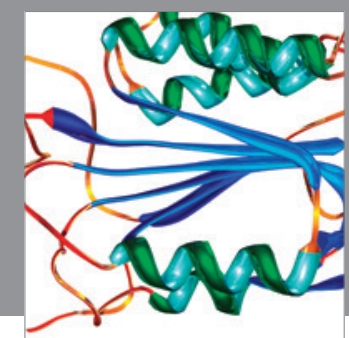

Disease Markers
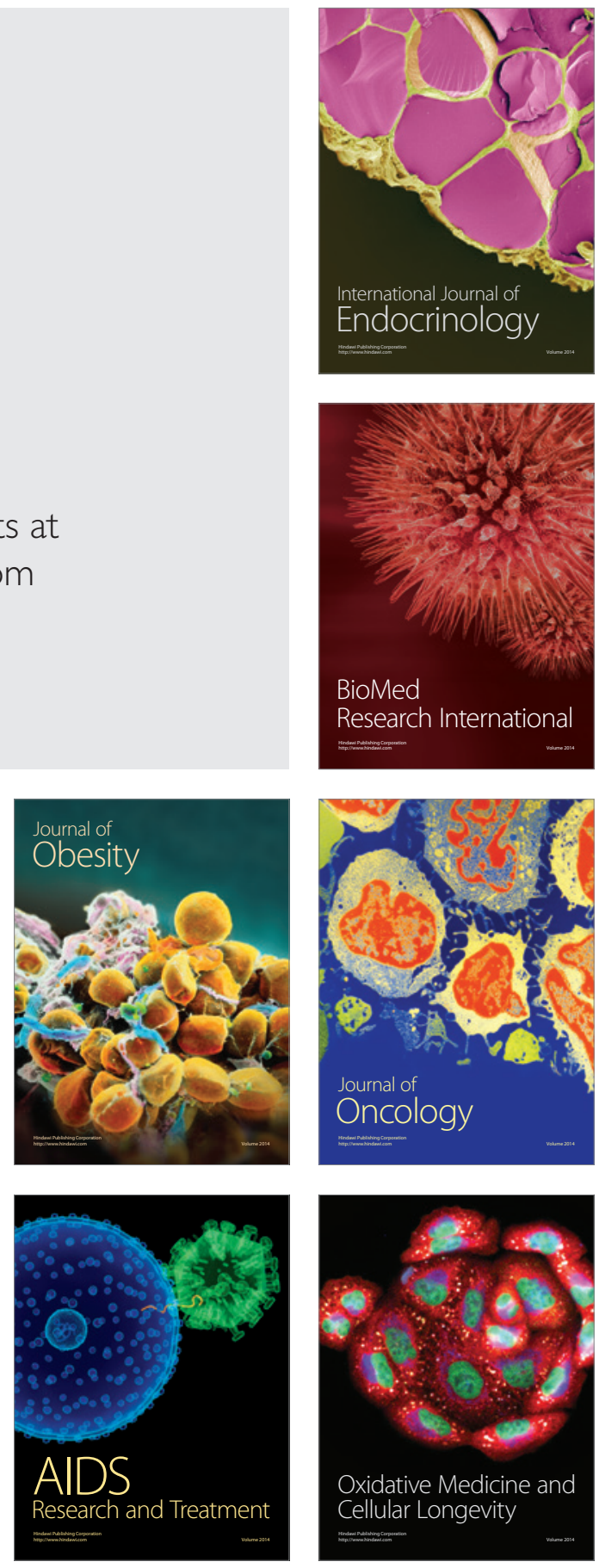